\title{
Somatostatin, substance $P$ and calcitonin gene-related peptide-positive intramural nerve structures of the human large intestine affected by carcinoma
}

\author{
Janusz Godlewski ${ }^{1}$, Jerzy Kaleczyc ${ }^{2}$ \\ ${ }^{1}$ Department of Human Histology and Embryology, Faculty of Medical Sciences, University of Warmia \\ and Mazury, Olsztyn, Poland \\ 2 Department of Animal Anatomy, Faculty of Veterinary Medicine, University of Warmia and Mazury, \\ Olsztyn, Poland
}

\begin{abstract}
The aim of this study was to investigate the arrangement and chemical coding of enteric nerve structures in the human large intestine affected by cancer. Tissue samples comprising all layers of the intestinal wall were collected during surgery form both morphologically unchanged and pathologically altered segments of the intestine ( $\mathrm{n}=15)$, and fixed by immersion in buffered paraformaldehyde solution. The cryostat sections were processed for double-labelling immunofluorescence to study the distribution of the intramural nerve structures (visualized with antibodies against protein gene-product 9.5) and their chemical coding using antibodies against somatostatin (SOM), substance P (SP) and calcitonin gene-related peptide (CGRP). The microscopic observations revealed distinct morphological differences in the enteric nerve system structure between the region adjacent to the cancer invaded area and the intact part of the intestine. In general, infiltration of the cancer tissue resulted in the gradual (depending on the grade of invasion) first decomposition and reduction to final partial or complete destruction and absence of the neuronal elements. A comparative analysis of immunohistochemically labeled sections (from the unchanged and pathologically altered areas) revealed a statistically significant decrease in the number of CGRP-positive neurons and nerve fibres in both submucous and myenteric plexuses in the transitional zone between morphologically unchanged and cancer-invaded areas. In this zone, a decrease was also observed in the density of SP-positive nerve fibres in all intramural plexuses. Conversely, the investigations demonstrated statistically insignificant differences in number of SP- and SOM-positive neurons and a similar density of SOM-positive nerve fibres in the plexuses of the intact and pathologically changed areas. The differentiation between the potential adaptive changes in ENS or destruction of its elements by cancer invasion should be a subject of further investigations.
\end{abstract}

Key words: enteric nervous system, somatostatin, SP, CGRP, carcinoma of the large intestine, immunohistochemistry, human

\section{Introduction}

The literature in the field contains many papers on the arrangement and neurochemical (immunohistochemical) properties of the enteric nerve structures in various mammalian species including humans [1-5]. Investigations performed under physiological conditions have demonstrated the expression of vasoactive intestinal peptide (VIP), neuropeptide Y (NPY), pituitary adenylate cyclase-activating polypeptide (PACAP), somatostatin (SOM), substance P (SP) and calcitonin gene-

Correspondence: J. Godlewski, 10-628 Olsztyn, Bankowców

Str. 35, Poland; tel.: (+48) 698694 528,

e-mail: janusz350@poczta.onet.pl related peptide (CGRP) in nerve elements of the enteric nervous system (ENS) supplying the human large intestine [1,6-13]. Some studies have also revealed profound morphological and functional changes in the ENS associated with pathological conditions of the colon [14-16]. They include alterations in neuropeptides expression in the intramural nerve elements. Currently, no information is available on the state of ENS during invasion of cancer in the human large intestine. Consequently, there is also no information on both autonomic and sensory innervation involved in the contraction and diastole of the intestine in the pathologically altered area. Studies performed on laboratory animals have revealed an increase in the density of SP- and VIP-expressing nerve fibres in the 
Table 1. List of primary antibodies and secondary reagents used in this study.

\begin{tabular}{|c|c|c|c|c|}
\hline Antigen & Code & Species of origin & Dilution & Source \\
\hline \multicolumn{5}{|c|}{ Primary antiscra } \\
\hline$P G P-9,5$ & $13 \mathrm{C} 4$ & mouse & 1 in 2000 & Biogenesis, UK \\
\hline CGRP & RPN 1842 & rabbit & 1 in 1600 & Amersham, UK \\
\hline $\mathrm{SOM}$ & 7.00926 & rabbit & 1 in 1000 & Amersham, UK \\
\hline SOM & 18050575 & rat & 1 in 50 & Chemicon, UK \\
\hline $\mathrm{SP}$ & 4047 & rabbit & 1 in 600 & Biomeda Corp. US $\Lambda$ \\
\hline \multicolumn{5}{|c|}{ Secondary antisera } \\
\hline \multicolumn{3}{|c|}{ FITC-conjugated goat anti-mouse IgG } & 1 in 400 & Cappel, USA \\
\hline \multicolumn{3}{|c|}{ Biotinylated goat anti-rabbit $\lg G$} & 1 in 400 & Cappcl, USA \\
\hline \multicolumn{3}{|c|}{ Biotinylated goat anti-rat $\operatorname{lgG}$} & 1 in 400 & Cappcl, USA \\
\hline \multicolumn{3}{|c|}{ Streptavidin-conjugated CY 3} & 1 in 3000 & Jackson Immun. Lab., USA \\
\hline
\end{tabular}

muscle membrane of the intestine and, simultaneously, no changes have been observed in the number of SPand VIP-ergic enteric neurons in the course of colorectal carcinoma [17]. Investigations dealing with other organs of the human alimentary tract have demonstrated the presence of nerve fibres containing $\mathrm{SP}$ in oesophagus and stomach cardia cancer tissues [18]. It should be noted, that somatostatin analogues are used in treatment of gastrointestinal and pancreatic neuroendocrine tumors $[19,20]$. CGRP and SP, in turn, are commonly considered to be markers of sensory nerve elements, and are also thought to play an essential role in pathogenesis of inflammatory processes [21-23].

Therefore, the present study was aimed at determining the potential plasticity of ENS elements expressing immunoreactivity to SOM, CGRP and SP in the human sigmoid colon and rectum affected by carcinoma. The results obtained from the pathologically altered areas were compared with those obtained from the morphologically unchanged parts of the intestines.

\section{Materials and methods}

Tissue samples. The material to be examined originated from patients following surgery for carcinoma of the sigmoid colon and rectum at the Deparment of Oncological Surgery, Hospital of the Ministry of Interior Affairs and Administration in Olsztyn (Bioethical Commission permit No. 107/2004/II, Warmia and Mazury District Medical Association, Poland). The material was collected during surgery, i.e. resection of the anterior sigmoid colon and anterior amputation of the rectum, from patients in good general state, without any other significant diseases. An assumption was made in the study that the patients involved were free of such symptoms as: intestinal obstruction or sub-obstruction, constipation and inflammatory states of intestines. Patients after neoadjuvant radiotherapy were also excluded. In the period from July 2004 till June 2005, samples of material were collected from fifteen patients (nine women and six men). The mean age of the patients was 63.0 years (range: 41-78 years). From the dissected section of the intestine, two small specimens of its whole wall (ca. $2-1 \mathrm{~cm}$ in size) were collected. One specimen was collected from the segment of the intestine infiltrated with neoplasmic lesion, while the other was collected from the macroscopically-intact intestine, at least $5 \mathrm{~cm}$ away from the tumour.

Immunohistochemistry. For immunohistochemical analyses, the collected specimens (control and pathological) of the intestinal wall were fixed for 2 hours in $4 \%$ buffered ( $\mathrm{pH} 7.4$ ) paraformaldehyde, then rinsed in a phosphate buffer $(\mathrm{pH} 7.4)$ for 24 hours and transferred to and stored in $18 \%$ buffered ( $\mathrm{pH} 7.4$ ) sucrose solution until further processing. Ten $\mu \mathrm{m}$-thick cryostat sections of the tissue samples were processed for double-labeling immunofluorescence (according to an earlier described method) [24] to study the distribution of the intramural nerve structures (visualized with antibodies against protein gene-product 9.5; PGP 9.5) and their chemical coding using antibodies (listed in Table 1) against SOM, SP and CGRP. Thus, each mixture of primary antibodies applied contained antibodies against PGP 9.5 (to easily recognize the enteric nerve structures) and those against one of the biologically active substances mentioned.

The labelled sections were viewed under a Zeiss Axiophot microscope equipped with epi-fluorescence and an appropriate filter set for fluorescein isothiocyanate (FITC; B block) and Cy3 (G1 block). They were also investigated and images were recorded with Bio-Rad MR/2A confocal laser scanning microscope. Standard controls, i.e. preabsorption for the neuropeptide antisera $(20 \mu \mathrm{g}$ of appropriate antigen per $1 \mathrm{ml}$ of corresponding antibody at working dilution; all antigens purchased from Bachem, Sigma or Dianova), and omission and replacement of all primary antisera by nonimmune sera were applied to test antibody and method specificity.

To determine percentages of particular neuronal populations, at least 400 of PGP 9.5-positive neuronal profiles investigated for the expression of one of the biologically active substances were counted in each gangionated intestinal plexus (myenteric, and inner and outer submucosal) in every patient. As regards the cancer-invaded area, the analyses concerned intramural nerve elements found in the transitional zone between the morphologically unchanged and pathologically altered regions, where the structure of the intramural plexuses was relatively well preserved. The sections stained for 
Table 2. Percentage of CGRP, SP and SOM-ergic neurons present in submucous plexus in control and pathological sections.

\begin{tabular}{|l|c|c|c|c|c|}
\hline \multirow{2}{*}{} & \multicolumn{2}{|c|}{ Control sections } & \multicolumn{2}{c|}{ Pathological sections } \\
\cline { 2 - 6 } & $\begin{array}{c}\text { Mean percentage } \\
\text { of neurons }\end{array}$ & $\begin{array}{c}\text { Standard deviation } \\
\text { in } \%\end{array}$ & $\begin{array}{c}\text { Mean percentage } \\
\text { of neurons }\end{array}$ & $\begin{array}{c}\text { Standard deviation } \\
\text { in } \%\end{array}$ & $\begin{array}{c}\text { I.evel of statistical significance } \\
\text { at } p \leq 0.05\end{array}$ \\
\hline CGRP & 45.3 & 16.0 & 29.6 & 17.0 & 0.012 \\
\hline SP & 38.5 & 10.0 & 30.6 & 10.5 & 0.054 \\
\hline SOM & 30.6 & 10.3 & 23.6 & 9.7 & 0.069 \\
\hline
\end{tabular}

Table 3. Percentage of CGRP, SP and SOM-ergic neurons present in the myenteric plexus in control and pathological sections

\begin{tabular}{|c|c|c|c|c|c|}
\hline \multirow{2}{*}{} & \multicolumn{2}{|c|}{ Control sections } & \multicolumn{2}{c|}{ Pathological sections } \\
\cline { 2 - 6 } & $\begin{array}{c}\text { Mean percentage } \\
\text { of ncurons }\end{array}$ & $\begin{array}{c}\text { Standard deviation } \\
\text { in } \%\end{array}$ & $\begin{array}{c}\text { Mean percentage } \\
\text { of neurons }\end{array}$ & $\begin{array}{c}\text { Standard deviation } \\
\text { in } \%\end{array}$ & $\begin{array}{c}\text { T.evel of statistical significance } \\
\text { at p } \leq 0.05\end{array}$ \\
\hline CGRP & 42.1 & 14.3 & 31.0 & 12.2 & 0.047 \\
\hline SP & 37.0 & 8.9 & 36.2 & 12.8 & 0.778 \\
\hline SOM & 34.8 & 10.1 & 26.8 & 10.8 & 0.061 \\
\hline
\end{tabular}

the same combination of the antigens assigned to quantitative investigations were separated by at least $100 \mu \mathrm{m}$ to avoid doubleanalysis of neuronal somata. All results are expressed as means \pm S.E.M. Simultaneously, the same preparations were analyzed for nerve fibres. The estimated number of fibres was scored as follows: (0) - a lack of fibres, $(+)$ - a low density of nerve fibres, $(++)$ - a medium density of nerve fibres, and $(+++)-$ a high density of nerve fibres.

Statistical analysis. The non-parametric U Mann-Whitney test was used to analyze percentage variability in the concentration of neurons, whereas the -Kendall rank coefficient - to evaluate changes in the density of nerve fibres $[25,26]$.

\section{Results}

Immunostainings against PGP 9.5 revealed three well developed ganglionated plexuses in the wall of the intact human large intestine (Figs. 1,3,5). They included the myenteric (Auersbach's) plexus located between the longitudinal and circular muscle layers of the intestinal muscle coat, and two submucosal plexuses, inner (Meissner's) and outer (Schabadasch's), found between the muscularis mucosa and lamina propria and in the submucosa, respectively. The microscopic observations revealed distinct morphological differences in ENS structure between the region adjacent to the cancer invasion and the intact part of the intestine. In general, infiltration of the cancerous tissue resulted in the gradual (depending on the grade of the invasion) first decomposition and reduction to final partial or complete destruction and absence of the neuronal elements.

Double-labelling immunohistochemistry revealed the presence of many neurons expressing immunoreactivity to SOM, SP and CGRP in both submucosal plexuses (30.6, 38.5 and $45.3 \%$, respectively) and in the myenteric plexus $(34.8,37$ and 42.1$)$ in the intact region of the large intestine (Tables 2,3). Nerve fibres immunoreactive to all the substances investigated were also found in particular layers of the intestinal wall (Figs. 1,3,5). In general those immunoreactive to SP and CGRP slightly outnumbered those stained for SOM.

The most remarkable difference in the chemical coding of the enteric neurons between the unchanged and pathologically changed parts of the intestine included a very decreased number of CGRP-positive nerve cells in both submucosal and myenteric plexuses (down to approx. $29.6 \%$ and $31 \%$, respectively; Tables 2,3) of the cancer infiltrated region. The percentages of the neurons stained for the remaining substances in the submucosal plexuses as well as the chemical coding of the nerve cells in the myenteric plexus were comparable (differences statistically insignificant) in both regions of the intestine. There were also no clear-cut differences in the distribution of the intramural nerve fibre populations expressing immunoreactivity to SOM SP and CGRP between the intact and cancer affected parts if the intestine. However, their density varied significantly (Figs. 7,8). In general, a distinct decrease in the number of SP- and CGRP-, and a slight decrease in the number of SOM-positive fibres was found in the submucosal plexuses from the pathologically changed region. In the myenteric plexus of this area, the density of SP- and, especially CGRP-positive fibres was distinctly lower, while the density of SOM-immunoreactive fibres was assessed to be only slightly reduced. 


\section{Discussion}

The present study has revealed that the morphology and chemical coding of intramural nerve structures in the region of the human large intestine affected by cancer markedly differ from those found in the neighboring, intact areas. As expected, infiltration of the cancer tissue resulted in the gradual (depending on the grade of invasion) first decomposition and reduction to final partial or complete destruction and absence of the neuronal elements in the wall of the invaded region of the intestine.

Immunohistochemical studies have demonstrated the expression of CGRP in neurons and nerve fibres in the submucous and myenteric plexuses in the human small intestine [12] as well as in the small and large intestine of guinea pig and pig [27-31]. Immunohistochemical colocalization investigations have revealed that in the submucous plexuses, CGRP is expressed by local sensory neurons or cholinergic secretomotor neurons. It was also shown that in the myenteric plexus, some cholinergic secreto-motor neurons and cholinergic interneurons exhibited immunoreactivity for this peptide [29,31]. Moreover, nerve fibres of the CGRPergic neurons were found around blood vessels of the submucous tissue [32]. Publications addressing the problem of variability of CGRP-ergic component of innervation of the human large intestine invaded by cancer are lacking and there have been no similar studies conducted on animals.

For this reason, an analysis of studies conducted to date on the variability of intestinal innervation in other diseases than cancer might prove to be useful in the interpretation of the present results. In acute colitis experimentally induced in laboratory animals, an early decrease in the density of CGRP-positive nerve fibres and an early decrease in CGRP tissue concentration in all layers of the intestinal wall have been found. After this early decrease, there occurred a successive increase in the number of CGRP-positive neurons and nerve fibres, and return of these neural parameters to the primary levels [21-23].

In the experimental study, time and dynamics of a disease could be estimated, but in the neoplasmic process the time span from the beginning of the process could not be precisely determined. In the present study, analyses demonstrated a statistically significant decrease in the number of CGRP-positive neurons and nerve fibres in both submucous and myenteric plexuses of the cancer affected intestine. The decline in CGRP-expressing component of the enteric innervation found in this study could be due to the permanent and strong stimulation of the sensory innervation of the affected part of the colon. Acceptance of such an assertion would allow the presumption that patients could suffer pain evoked by lesions in the colon during cancer invasion in the intestinal wall.
The presence of SP-positive neurons and nerve fibres has been found in the submucous plexus of the human small and large intestine $[1,9,10]$. Immunohistochemical colocalization investigations have revealed that SP-positive enteric neurons innervating guinea pig and pig intestines belong to the population of local sensory and cholinergic secreto-motor nerve cells. In the myenteric plexus, neurons expressing SP have been found to belong to a class of sensory and cholinergic interneurons, and also cholinergic secreto-motor neurons [27-30,33-35]. SP has been found to stimulate the muscular memmbrane of the intestine, thus inducing its contraction by the direct mechanism of action and by indirect mechanism consisting in the stimulation of cholinergic neurons [3,36]. Apart from the above-presented effect of SP on the contractility of the muscular memmbrane of the intestinal wall, this neuropeptide, by presence in sensory neurons, also enhances secretion of mucous membrane glands in the large intestine and affects blood flow in the intestinal wall $[10,32,37]$. The available literature contains no information on the plasticity of the enteric SP-positive nerve system in human colorectal carcinoma. The presence of SP-positive fibres in cancer infiltration was also detected in others organs of the alimentary tract such as oesophagus and stomach cardia carcinoma [18]. In experimental study of colorectal cancer in animals, an increase in the density of SP-positive nerve fibres was observed in the muscular layer of the intestine affected by the disease [17]. In non-cancerous pathological states of the large intestine, e.g. colonic diverticulosis, and also in habitual constipation, no changes have been found in the number of SP-positive neurons or nerve fibres of the intestinal wall $[38,39]$. Analyses conducted in ulcerating colitis demonstrated an increase in the number of SP-positive neurons in the myenteric plexus an increase in the density of SP-positive nerve fibres in particular layers of the intestinal wall $[40,41]$. Reports describing the plasticity of SPpositive innervation in the inflammatory states of intestine indicate that such changes proceed in the active phase of the disease, which might confirm that SP, considered as a mediator of the inflammatory process, may actually be one of the pro-inflammatory factors. This may be indicated by an increase in SP tissue content of the intestinal wall, which may induce neurogenic inflammation by, among others, dilatation of blood vessels, mast cell degranulation and release of histamine from the mucous membrane [23]. In the present study, a statistically insignificant decrease was observed in the number of SP-positive neurons in the submucous plexuses of the pathologically changed as compared to the unchanged part of the intestine. The number of neurons in the myenteric plexus was similar in both of these areas. In contrast, a decrease was observed in the density of SP-positive nerve fibres in 

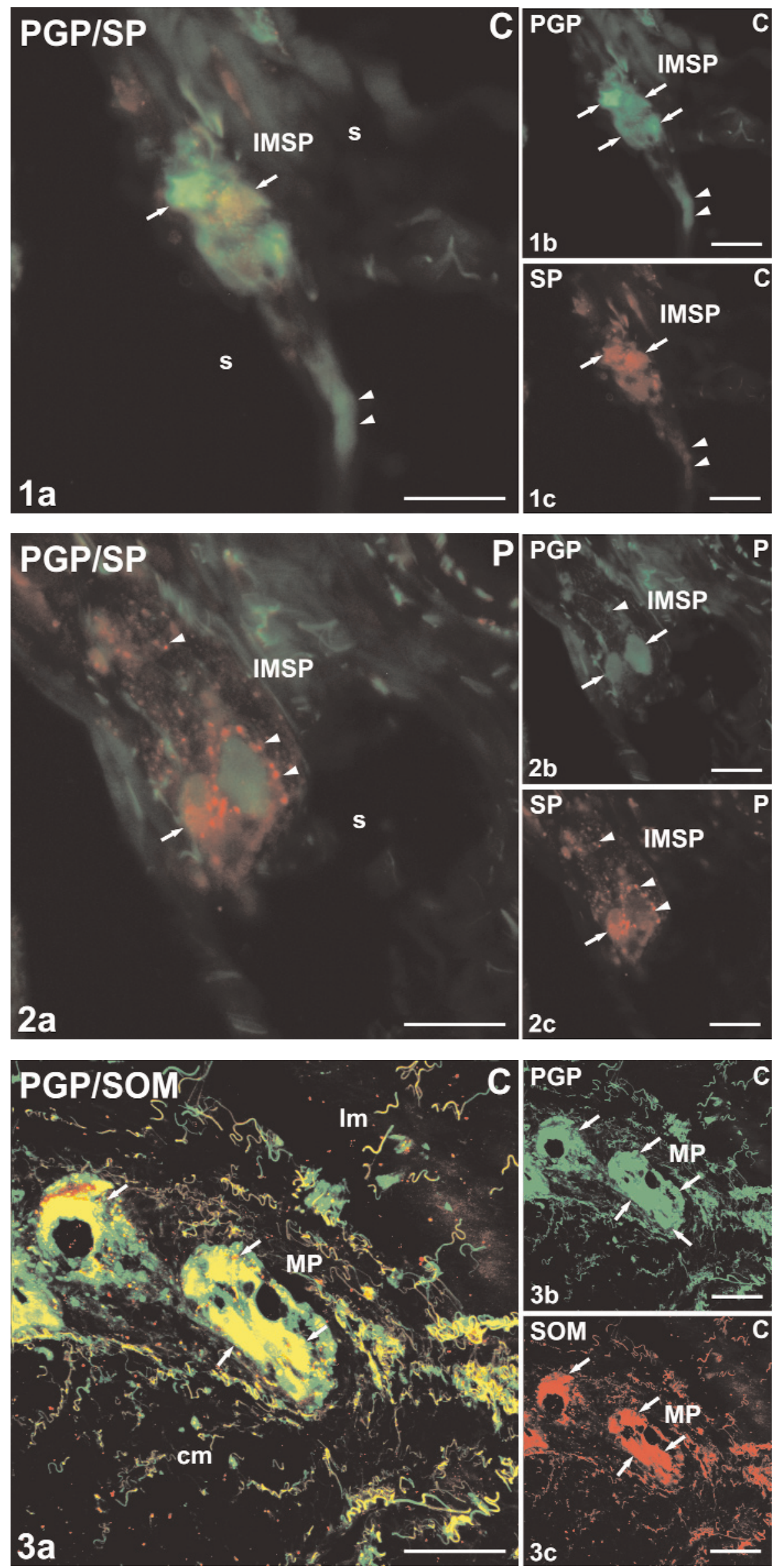

Fig. 1. The inner submucosal plexus (IMSP) in a section from the intact part of the intestine. Fluorescent microscope (FM) image showing neurons expressing PGP-9.5 (1b) and SP (1c).The images were superimposed (1a), double-labeled (PGP-9.5 and SP-positive) neurons are yellow. The SP-positive neuron (arrow) and nerve fibres (spearheads) around SPnegative neuron are visible. Bar $=60 \mu \mathrm{m}$.

Fig. 2. The IMSP in a section from the cancer affected part of the intestine. FM image showing the distribution of neurons expressing PGP-9.5 (2b) and SP (2c). The images were superimposed (2a), doublelabeled (PGP-9.5 and SP-positive) neurons are yellow. SP-positive neurons (arrows) and nerve fibres (spearheads) are visible. $\mathrm{Bar}=60 \mu \mathrm{m}$

Fig. 3. The myenteric plexus (MP) in a section from the intact part of the intestine. Confocal laser scaning microscope (CLSM) image showing the distribution of neurons expressing PGP-9.5 (3b) and SOM (3c). The images were superimposed (3a), double- labeled (PGP-9.5 and SOM-positive) neurons are yellow. Neurons (arrows) and nerve fibres (spearheads) form the normal structure of MP. $\mathrm{Bar}=60 \mu \mathrm{m}$. 

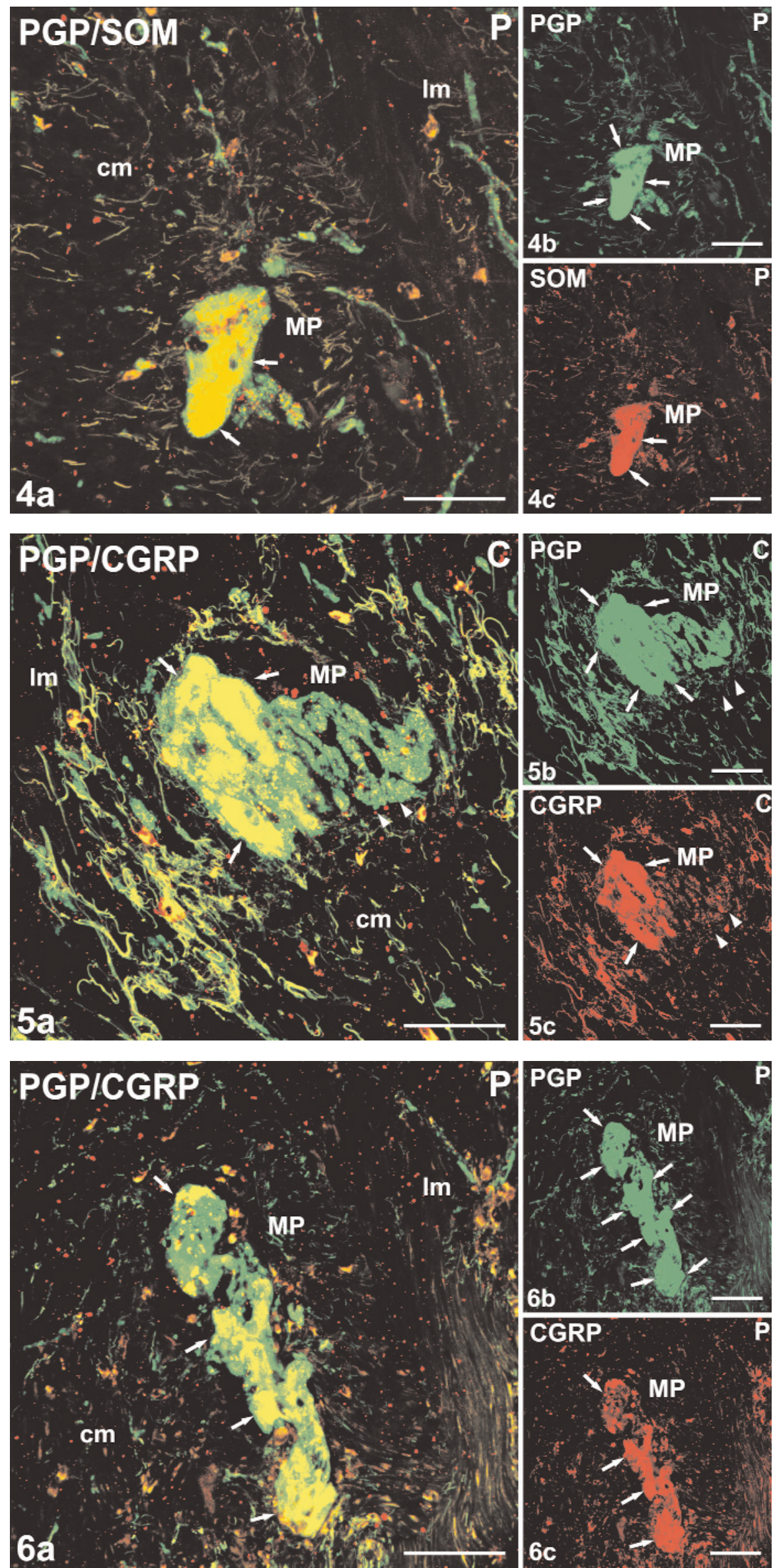

Fig. 4. The MP in a section from the cancer affected part of the intestine. CLSM image showing the distribution of neurons expressing PGP-9.5 (4b) and SOM (4c). The images were superimposed (4a), double-labeled (PGP-9.5 and SOM-positive) neuron is yellow. This plexus was almost totally destroyed and thus very small numbers of nerve fibres could be encountered there. $\mathrm{Bar}=60 \mu \mathrm{m}$

Fig. 5. The MP in a control section. CLSM image showing neurons expressing PGP9.5 (5b) and CGRP (5c). These images were superimposed (5a), double labelled (PGP-9.5 and CGRP -positive) neurons are yellow. The normal structure of the myenteric plexus is visible. Almost all neurons (arrows) and majority of nerve fibres (spearheads) are CGRP -positive. Bar $=60 \mu \mathrm{m}$.

Fig. 6. The MP in a pathological section. CLSM image showing the distribution of neurons expressing PGP-9.5 (6b) and CGRP (6c). These images were superimposed (6a), double labelled (PGP-9.5 and CGRP -positive) neurons are yellow. The presented plexus has smaller size than in control sections. This were usually observed features of myenteric plexuses located close to tissue of cancer invasion. All neurons (arrows) are very small and nerve fibres (spearheads) are in very low density in this plexus. Part of neurons are CGRP -positive. Bar $=60 \mu \mathrm{m}$. 

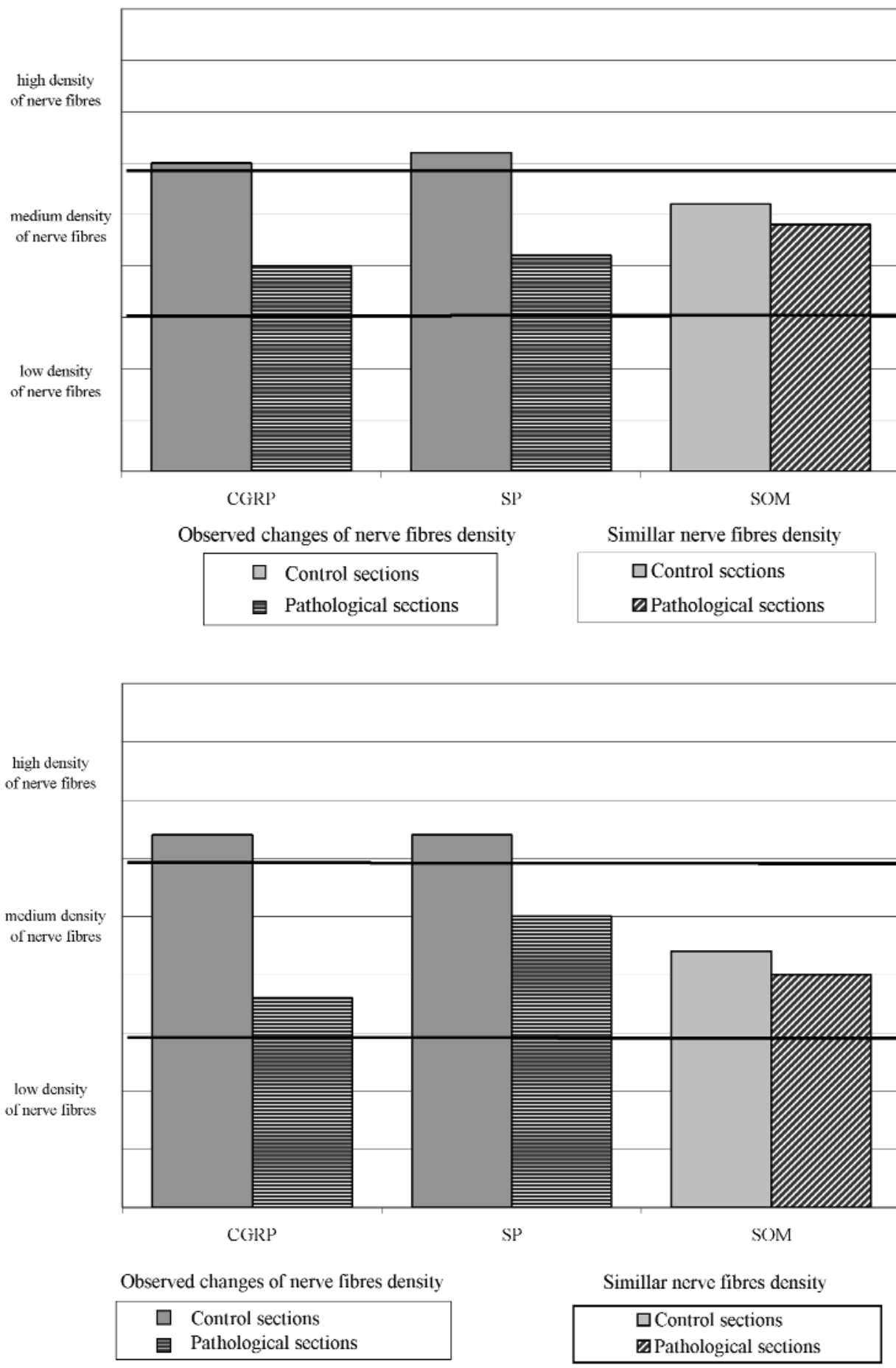

Fig. 7. Changes in the density of nerve fibres in submucous plexuses in control and pathological sections.
Fig. 8. Changes in the density of nerve fibres in myenteric plexuses in control and pathological sections. all plexuses of the intestinal wall in the cancer affected region. The statistically insignificant decrease in the number of SP-positive neurons in the submucous pelxuses and the decrease in density of the SP-positive nerve fibres demonstrated in the neoplasmic infiltration analyzed are likely to be explained by strong stimulation of the SP-expressing afferent nerves by the cancer tissue damaging the intestinal walls. The observed decline in the SP-positive innervation in the submucous tissue may result in diminished intestinal secretion determined by the SP-ergic secreto-motoric innervation. The fact that SP is located in the secretomotor neurons of the myenteric plexus and that it induces contraction of intestinal muscles, as well as a compilation of this information with the demonstrated lack of changes in the number of SP-ergic neurons of the myenteric plexus in the pathologically changed areas, are likely to indicate the preserved contractive 
function of the intestine determined by the SP-ergic innervation. The changes observed in this study, which consist of the diminished density of the SP-ergic nerve fibres in all layers of the intestine, are similar to late changes taking place during the destruction of a pig intestinal wall infected by the parasite Schistosoma japonicum [42].

The presence of the SOM-ergic neurons was confirmed in plexuses of all layers of the human small and large intestine [11,13], as well as in the small and large intestine of the guinea pig and in the small intestine of the pig [29,30]. Immunohistochemical colocalization studies have revealed that these neurons belong to the population of cholinergic secreto-motor neurons. In the myenteric plexus, they were classified as cholinergic secreto-motor and also, secreto-motor as well as cholinergic and noncholinergic interneurons $[29,31,43]$. As revealed by physiological studies, SOM is a neurotransmitter inhibiting intestinal muscle tonus [2].

In references published to date, there is no information on the plasticity of SOM-ergic innervation in the course of colorectal carcinoma in humans. Similar studies are also lacking in animals. Sparse reports are also available on the problem of the plasticity of SOMergic innervations in other pathologies of the intestines in both humans and animals. For this reason, referring the results obtained in this study to other findings related to this problem is obviously difficult. The present study demonstrated a statistically insignificant decrease in the number of neurons in the submucous and myenteric plexuses of the cancer affected as compared to the intact intestinal region. No changes were observed in turn in the density of SOM-positive nerve fibres in these plexuses of both intestinal segments examined.

In compiling the present results with the recognized role of SOM in the inhibition of the intestinal muscle tonus, it may be speculated that the statistically insignificant changes in SOM-ergic innervation of the large intestine proceeding in neoplasmic invasion may result from the increased tonus of the affected part of the intestine. Likewise, a decreased number of SOMpositive neurons in the submucous plexusr observed in the cancer affected area, due to their secreto-motor function, is likely to result in the inhibition of the intestinal secretion.

The present study has revealed distinct changes in the arrangement and chemical coding of intramural neural components in the region of the colonic wall adjacent to cancer invasion. The differentiation between the potential adaptive changes in ENS or destruction of its elements by cancer invasion should be a subject of further investigations.

Acknowledgments: The authors wish to thank Mrs. G. Greniuk and Mr. A. Penkowski for technical assistance and Dr E. Wędrowska for the statistical analysis.

\section{References}

[ 1] Crowe R, Kamm MA, Burnstock G, Lennard-Jones JE Peptide-containing neurons in different regions of the submucous plexus of human sigmoid colon. Gastroenterology. 1992;102:461-467.

[2] Surprenant A. Control of the gastrointestinal tract by enteric neurons. Annu Rev Physiol. 1994;56:117-140.

[ 3] Costa M, Brookes SJ. The enteric nervous system. Am J Gastroenterol. 1994;89:S129-S137.

[4] Furness JB, Young HM, Pompolo S, Bornstein JC, Kunze WA, McConalogue K. Plurichemical transmission and chemical coding of neurons in the digestive tract. Gastroenterology. 1995;108:554-563.

[5] Schemann M, Neunlist M. The human enteric nervous system. Neurogastroenterol Motil. 2004;16 Suppl 1:55-59.

[6] Wattchow DA, Furness JB, Costa M. Distribution and coexistence of peptides in nerve fibers of the external muscle of the human gastrointestinal tract. Gastroenterology. 1988;95:3241.

[ 7] Domoto T, Bishop AE, Oki M, Polak JM. An in vitro study of the projections of enteric vasoactive intestinal polypeptideimmunoreactive neurons in the human colon. Gastroenterology. 1990;98:819-827.

[ 8] Sundler F, Ekblad E, Absood A, Hakanson R, Koves K, Arimura A. Pituitary adenylate cyclase activating peptide: a novel vasoactive intestinal peptide-like neuropeptide in the gut. Neuroscience. 1992;46:439-454.

[ 9] Ferri GL, Botti PL, Vezzadini P, Biliotti G, Bloom SR, Polak JM. Peptide-containing innervation of the human intestinal mucosa. An immunocytochemical study on whole-mount preparations. Histochemistry. 1982; 76:413-420.

[10] Llewellyn-Smith IJ, Furness JB, Murphy R, O'Brien PE, Costa M Substance P-containing nerves in the human small intestine. Distribution, ultrastructure, and characterization of the immunoreactive peptide. Gastroenterology. 1984;86:421435.

[11] Keast JR, Furness JB, Costa M. Somatostatin in human enteric nerves. Distribution and characterization. Cell Tissue Res. 1984;237:299-308.

[12] Timmermans JP, Scheuermann DW, Barbiers M. et all. Calcitonin gene-related peptide-like immunoreactivity in the human small intestine. Acta Anat (Basel). 1992;143:48-53.

[13] Hens J, Vanderwinden JM, De Laet MH, Scheuermann DW, Timmermans JP. Morphological and neurochemical identification of enteric neurones with mucosal projections in the human small intestine. J Neurochem. 2001;76:464-471.

[14] Koch TR, Carney JA, Go VL. Distribution and quantitation of gut neuropeptides in normal intestine and inflammatory bowel diseases. Dig Dis Sci. 1987;32:369-376.

[15] Belai A, Boulos PB, Robson T, Burnstock G. Neurochemical coding in the small intestine of patients with Crohn's disease. Gut. 1997;40:767-774.

[16] Lomax AE, Fernandez E, Sharkey KA. Plasticity of the enteric nervous system during intestinal inflammation. $\mathrm{Neu}$ rogastroenterol Motil. 2005;17:4-15.

[17] Sitohy B, El Salhy M. Changes in the colonic enteric nervous system in rats with chemically induced colon dysplasia and carcinoma. Acta Oncol. 2002;41:543-549.

[18] Lu SH, Zhou Y, Que HP, Liu SJ. Peptidergic innervation of human esophageal and cardiac carcinoma. World J Gastroenterol. 2003;9:399-403.

[19] Kos-Kudła B. Guzy neuroendokrynne. Endokrynologia Polska. 2004;55:492-498.

[20] Oberg K, Kvols L, Caplin M, et all Consensus report on the use of somatostatin analogs for the management of neuroendocrine tumors of the gastroenteropancreatic system. Ann Oncol. 2004;15:966-973. 
[21] Eysselein VE, Reinshagen M, Patel A, Davis W, Nast C, Sternini C. Calcitonin gene-related peptide in inflammatory bowel disease and experimentally induced colitis. Ann NY Acad Sci. 1992;657:319-327.

[22] Miampamba M, Sharkey KA. Distribution of calcitonin generelated peptide, somatostatin, substance $\mathrm{P}$ and vasoactive intestinal polypeptide in experimental colitis in rats. Neurogastroenterol Motil. 1998;10:315-329.

[23] Sharkey KA, Kroese AB. Consequences of intestinal inflammation on the enteric nervous system: neuronal activation induced by inflammatory mediators. Anat Rec. 2001;262:7990.

[24] Kaleczyc J, Timmermans JP, Majewski M, Lakomy M, Scheuermann DW. Immunohistochemical properties of nerve fibres supplying accesory male genital glands in the pig. A clocalisation study. Histochem Cell Biol. 1999;11,217-228.

[25] Kowal J. Metody statystyczne w badaniach sondazowych rynku. PWN Warszawa; 1998.

[26] Sobczyk M. Statystyka. PWN Warszawa; 2000.

[27] Timmermans JP, Scheuermann DW, Stach W, Adriaensen D, Groodt-Lasseel MH. Distinct distribution of CGRP-, enkephalin-, galanin-, neuromedin U-, neuropeptide Y-, somatostatin-, substance P-, VIP- and serotonin-containing neurons in the two submucosal ganglionic neural networks of the porcine small intestine. Cell Tissue Res. 1990;260:367-379.

[28] Timmermans JP, Scheuermann DW, Stach W, Adriaensen D, Groodt-Lasseel MH. Functional morphology of the enteric nervous system with special reference to large mammals. Eur J Morphol. 1992;30:113-122.

[29] Timmermans JP, Adriaensen D, Cornelissen W, Scheuermann DW. Structural organization and neuropeptide distribution in the mammalian enteric nervous system, with special attention to those components involved in mucosal reflexes. Comp Biochem Physiol A Physiol. 1997;118:331-340.

[30] Hens J, Schrodl F, Brehmer A. et al. Mucosal projections of enteric neurons in the porcine small intestine. J Comp Neurol. 2000;421:429-436.

[31] Lomax AE, Furness JB. Neurochemical classification of enteric neurons in the guinea-pig distal colon. Cell Tissue Res. 2000;302:59-72

[32] Ekblad E, Ekman R, Hakanson R, Sundler F. Projections of peptide-containing neurons in rat colon. Neuroscience. 1988;27:655-674.

[33] Brookes SJ, Steele PA, Costa M. Identification and immunohistochemistry of cholinergic and non-cholinergic circular muscle motor neurons in the guinea-pig small intestine. Neuroscience. 1991;42:863-878.

[34] Brookes SJ, Song ZM, Steele PA, Costa M. Identification of motor neurons to the longitudinal muscle of the guinea pig ileum. Gastroenterology. 1992;103:961-973.

[35] Hens J, Gajda M, Scheuermann DW, Adriaensen D, Timmermans JP. The longitudinal smooth muscle layer of the pig small intestine is innervated by both myenteric and submucous neurons. Histochem Cell Biol. 2002;117:481-492.

[36] Holzer P, Lembeck F. Neurally mediated contraction of ileal longitudinal muscle by substance P. Neurosci Lett. 1980; 17:101-105.

[37] Galligan JJ, Costa M, Furness JB. Changes in surviving nerve fibers associated with submucosal arteries following extrinsic denervation of the small intestine. Cell Tissue Res. 1988;253:647-656.

[38] Koch TR, Carney JA, Go L, Go VL. Idiopathic chronic constipation is associated with decreased colonic vasoactive intestinal peptide. Gastroenterology. 1988;94:300-310.

[39] Milner P, Crowe R, Kamm MA, Lennard-Jones JE, Burnstock G. Vasoactive intestinal polypeptide levels in sigmoid colon in idiopathic constipation and diverticular disease. Gastroenterology. 1990;99:666-675.

[40] Watanabe T, Kubota Y, Muto T. Substance P containing nerve fibers in ulcerative colitis. Int J Colorectal Dis. 1998; 13:61-67.

[41] Keranen U, Kiviluoto T, Jarvinen H, Back N, Kivilaakso E, Soinila S. Changes in substance P-immunoreactive innervation of human colon associated with ulcerative colitis. Dig Dis Sci. 1995;40:2250-2258.

[42] Balemba OB, Semuguruka WD, Hay-Schmidt A, Johansen MV, Dantzer V. Vasoactive intestinal peptide and substance Plike immunoreactivities in the enteric nervous system of the pig correlate with the severity of pathological changes induced by Schistosoma japonicum. Int $J$ Parasitol. 2001;31:1503-1514.

[43] Portbury AL, Pompolo S, Furness JB. et al. Cholinergic, somatostatin-immunoreactive interneurons in the guinea pig intestine: morphology, ultrastructure, connections and projections. J Anat. 1995;187( Pt 2):303-321.

Submitted: 16 August, 2009 Accepted after reviews: 20 January, 2010 